\title{
FORMULATION AND EVALUATION OF FLOATING ORAL IN SITU GEL OF DILTIAZEM HYDROCHLORIDE
}

\author{
A. MAHESWARAN, J. PADMAVATHY, V. NANDHINI, D. SARAVANAN, P. ANGEL ${ }^{*}$
}

Jaya College of Paramedical Sciences, College of Pharmacy, CTH Road, Thiruninravur, Chennai, Tamil Nadu, India 602024 Email: angelmpharm2016@gmail.com

Received: 27 Oct 2016, Revised and Accepted: 26 Dec 2016

\section{ABSTRACT}

Objective: The objective of the present study was to formulate and evaluate the floating in-situ gelling system of diltiazem hydrochloride.

Methods: Sodium alginate based diltiazem hydrochloride floating in situ gelling systems were prepared by dissolving hydroxyl propyl methyl cellulose (HPMC) in $25 \%$ of water, to which calcium carbonate and diltiazem hydrochloride were added with stirring to form, a proper and a homogenous dispersion of diltiazem hydrochloride. Meanwhile, $30 \%$ of water was heated to $60{ }^{\circ} \mathrm{C}$ on a hot plate to dissolve sodium alginate and cooled to $40{ }^{\circ} \mathrm{C}$. The resulting solution was added to HPMC solution and mixed well. To $5 \%$ of water at $60^{\circ} \mathrm{C}$, sodium methyl paraben was added and dissolved and cooled to $40{ }^{\circ} \mathrm{C}$ and was added to the above mixture and mixed well. The volume was adjusted finally to $100 \%$ with distilled water. Prepared formulae were evaluated for physicochemical properties, drug content, $\mathrm{pH}$, in vitro gelling capacity, in vitro buoyancy, viscosity, water uptake and in vitro drug release.

Results: Formulation variables such as type and concentration of viscosity enhancing polymer (sodium alginate) and HPMC affected the formulation viscosity, gelling properties, floating behavior, and in vitro drug release. Formulation F5 and F6 showed the floating time of 5 min and more than $20 \mathrm{~h}$ respectively. A significant decrease in the rate and extent of the drug release was observed with the increase in polymer concentration in in-situ gelling preparation. Formulation F4, F5, F6 were shown to have extended drug release until the end of $7 \mathrm{~h}$.

Conclusion: The prepared in situ gelling formulations of diltiazem hydrochloride could float in the gastric conditions and released the drug in a sustained manner. The present formulation was non-irritant, easy to administer along with good retention properties, better patient compliant and with greater efficacy of the drug.

Keywords: In-situ gel, Sodium alginate, Diltiazem hydrochloride, Floating, Drug release

(C) 2016 The Authors. Published by Innovare Academic Sciences Pvt Ltd. This is an open access article under the CC BY license (http://creativecommons.org/licenses/by/4.0/) DOI: http://dx.doi.org/10.22159/ijap.2017v9i1.15914

\section{INTRODUCTION}

Over the past $30 \mathrm{y}$, greater attention has been focused on the development of controlled and sustained drug delivery systems. The development of in situ gel systems have received considerable attention over the past few years due to the advantages are shown by this system like the ease of administration, reduced frequency of administration, improved patient compliance and comfort [1].

The in situ gel dosage form is a liquid before administration but converts into a gel that floats on gastric contents as it comes in contact with it [2]. Such gel conversions are due to one or more mechanisms such as physiological stimuli (e. g., temperature and $\mathrm{pH}$ ), physical changes in biomaterials (e. g., diffusion of solvent and swelling) and chemical reactions (e. g., enzymatic, ionic and photoinitiated polymerization) [3].

In situ gel formulations are one of the challenging drug delivery systems. Since various biodegradable polymers used for the formulation of In situ gels, faces many fabrication problems, difficult processability, use of organic solvents, burst effect and irreproducible drug release kinetics and the natural polymers show batch to batch variations [4].

Diltiazem hydrochloride is a calcium channel blocker which is widely used in the treatment of variant angina, hypertension, and supraventricular tachyarrhythmias. It works by relaxing the blood vessels so that heart does not have to pump as hard. It also increases the supply of blood and oxygen to the heart. High blood pressure is a common condition and when not treated it can cause damage to the brain, heart, blood vessels, kidney and other parts of the body. Damage to these organs may cause heart diseases, heart attack, heart failure, stroke, kidney failure, loss of vision.

Diltiazem hydrochloride is freely soluble in distilled water, chloroform and methanol. It is rapidly absorbed (90\%) after oral administration, but availability is only $30 \%-40 \%$ in systemic circulation and bioavailability varies between individuals. It has an elimination half-life of 3-5 h and is slightly prolonged after multiple dosing. Based on the above physical, chemical, biopharmaceutical properties and clinical relevance, diltiazem hydrochloride was selected as the drug candidate for developing floating oral in-situ gel for releasing the drug in a sustained manner. The objective of the present study was to develop diltiazem hydrochloride floating insitu gel which provides sustained release of the drug for the management of hypertension or angina pectoris.

\section{MATERIALS AND METHODS}

\section{Materials}

Diltiazem hydrochloride was purchased from Gluchem Chemicals, Hyderabad; Andhra Pradesh, sodium alginate was procured from Loba Chemicals Pvt. Limited, Mumbai, calcium carbonate and sodium bicarbonate were purchased from SD Fine-Chem limited, Mumbai, HPMC was purchased from Molychem, Mumbai, sodium citrate was procured from Qualigens, Mumbai, methylparaben and hydrochloric acid were purchased from Molychem, Mumbai. All other reagents were of analytical grade.

\section{Methods}

Preparation of in-situ gel

Floating in-situ gel formulations of diltiazem hydrochloride were prepared using compositions given in table $1[5]$.

\section{Evaluation}

\section{Physicochemical properties}

The colour, odour and taste of the formulated in-situ gel of diltiazem hydrochloride were determined as per the senses. 
Table 1: Composition of diltiazem hydrochloride In situ gel formulations

\begin{tabular}{|c|c|c|c|c|c|c|}
\hline \multirow[t]{2}{*}{ Ingredients } & \multicolumn{6}{|c|}{ Formulations in mg } \\
\hline & F1 & F2 & F3 & F4 & F5 & F6 \\
\hline Diltiazem $\mathrm{HCl}$ & 30 & 30 & 30 & 30 & 30 & 30 \\
\hline HPMC & 50 & 50 & 50 & 50 & 50 & 50 \\
\hline Sodium alginate & 50 & 100 & 150 & 200 & 250 & 300 \\
\hline Calcium carbonate & 50 & 50 & 50 & 50 & 50 & 50 \\
\hline Sodium bicarbonate & 50 & 50 & 50 & 50 & 50 & 50 \\
\hline Sodium citrate & 25 & 25 & 25 & 25 & 25 & 25 \\
\hline Methyl paraben & 10 & 10 & 10 & 10 & 10 & 10 \\
\hline
\end{tabular}

\section{Determination of drug content}

Accurately, $10 \mathrm{ml}$ of the formulation (containing the equivalent of $30 \mathrm{mg}$ diltiazem hydrochloride) from different batches was measured and transferred to $100 \mathrm{ml}$ volumetric flasks. To this $50-70 \mathrm{ml}$ of $0.1 \mathrm{~N} \mathrm{HCl}$ was added and sonicated for $30 \mathrm{~min}$. Volume was adjusted to $100 \mathrm{ml}$. Complete dispersion of the contents was ensured visually and the dispersion was filtered using Whatman's filter paper. From this solution, $10 \mathrm{ml}$ of sample was withdrawn and diluted to $100 \mathrm{ml}$ with $0.1 \mathrm{~N} \mathrm{HCl}$. Contents of diltiazem hydrochloride were measured at a maximum absorbance at $237 \mathrm{~nm}$ using UV-Visible spectrophotometer [5].

\section{pH measurement}

$\mathrm{pH}$ of the prepared formulations was measured using a calibrated digital $\mathrm{pH}$ meter at $27^{\circ} \mathrm{C}[6]$.

\section{In vitro gelation study}

To evaluate the formulation for their in vitro gelling capacity accurately measured $1 \mathrm{ml}$ of the coloured formulation were added to $5 \mathrm{ml}$ of the gelation solution $(0.1 \mathrm{~N} \mathrm{HCl}, \mathrm{pH} 1.2)$ at $37^{\circ} \mathrm{Cin}$ a test tube with mild agitation that avoids breaking of formed gel. The in vitro gelling capacity was graded in three categories on the basis of the stiffness of the formed gel, gelation time and time period for which they formed gel remains as such $(+)$ gels after few minutes, dispersed rapidly; (++) gelation immediate remains for few $\left.\mathrm{h} ; \mathrm{C}^{+++}\right)$ gelation immediate remains for an extended period.

\section{Measurement of viscosity of in-situ gelling system}

The viscosity of the dispersion was determined using a Brookfield digital viscometer (DV-E Viscometer). The samples $(2 \mathrm{ml}$ ) were sheared at a rate of $\mathrm{rpm} / \mathrm{min}$ using spindle number 1 at room temperature. Viscosity measurement for each sample was done in triplicate, with each measurement taking approximately 30 seconds [7-9].

\section{In vitro floating study}

The in vitro floating study was carried out by introducing $10 \mathrm{ml}$ of the formulation into a beaker containing $900 \mathrm{ml}$ of $0.1 \mathrm{~N} \mathrm{HCl} \mathrm{pH}$ 1.2) at $37^{\circ} \mathrm{C}$ without much disturbance. The time the formulation took to emerge on the medium surface (floating lag time) and the time the formulation constantly floated on the surface of the dissolution medium (Duration of floating) were recorded [10-12].

\section{Measurement of water uptake}

The water uptake by the gel of selected formulation of sodium alginate was determined by a simple method. In this study, the insitu gel formed in $40 \mathrm{ml}$ of $0.1 \mathrm{~N} \mathrm{HCl}(\mathrm{pH} \mathrm{1.2)}$ was used for each formulation the gel portion from the $0.1 \mathrm{~N} \mathrm{HCl}$ was separated, and the excess $\mathrm{HCl}$ solution was blotted out with a tissue paper. The initial weight of the gel taken was weighed, and to this gel, $10 \mathrm{ml}$ of distilled water was added and after every 30 min of the interval water was decanted and the weight of the gel was recorded and the difference in the weight was calculated [13,14].

\section{In vitro drug release study}

The dissolution studies were performed in triplicate using type I (basket method) dissolution apparatus. The dissolution medium used was $900 \mathrm{ml}$ of $0.1 \mathrm{~N} \mathrm{HCl}$ maintained at $37^{\circ} \mathrm{C}$. The stirring rate was adjusted to $50 \mathrm{rpm}$. This speed was believed to stimulate the in vivo existing mild agitation and was slow enough to avoid the breaking of gelled formulation. At predetermined time intervals $1 \mathrm{ml}$ samples were withdrawn and replaced by fresh dissolution medium, filtered through what Mann's filter paper, diluted and assayed at a maximum absorbance at $237 \mathrm{~nm}$ using double beam UV-Visible spectrophotometer [15-17].

\section{RESULTS AND DISCUSSION}

In this study, six formulations of sodium alginate based floating oral in-situ gelling systems of diltiazem hydrochloride were prepared using sodium alginate as release retarding gel forming a polymer. Viscosity enhancing polymer HPMC was added to sodium alginate solution in an attempt to improve viscosity and to obtain slower drug release than those formulations containing sodium alginate alone. Calcium carbonate was used as a source of calcium ions and as a gas generating agent [18]. In addition sodium, bicarbonate was also included in the formulations as an additional gas generating agent to enhance floating behaviour of the In situ gelling system of diltiazem hydrochloride.

\section{Physicochemical properties}

The formulated oral In situ gelling system of diltiazem hydrochloride was found to be off white in colour with characteristic odour and a bland taste.

\section{Drug content}

The percentage drug content for all formulation was determined and shown in table 2. The drug content was found to be in the range of $105-120 \%$ for all the formulations indicating a uniform distribution of the drug.

\section{pH measurement}

The measurement of $\mathrm{pH}$ is very important for oral preparations. Otherwise, it leads to irritation to the throat. All the formulations had a slightly alkaline $\mathrm{pH}$. The $\mathrm{pH}$ of formulations was found in the range of 8.15-8.30 as shown in table 2.

Table 2: Evaluation of in-situ gel $(n=3)$ (average \pm SEM)

\begin{tabular}{|c|c|c|c|c|c|c|}
\hline Formulation code & Drug content (\%) & pH & Gelling study & Floating lag time (min) & Duration of floating & Viscosity (cps) \\
\hline F1 & $109.2 \pm 0.51$ & $8.15 \pm 0.03$ & $(+)$ & $x_{2}=0$ & Did not float & $4.97 \pm 0.01$ \\
\hline F2 & $105.9 \pm 0.44$ & $8.26 \pm 0.03$ & $(+)$ & - & Did not float & $22.093 \pm 0.01$ \\
\hline F3 & $108.2 \pm 0.38$ & $8.27 \pm 0.02$ & $(+)$ & - & Did not float & $884.269 \pm 0.01$ \\
\hline $\mathrm{F} 4$ & $118.2 \pm 0.44$ & $8.29 \pm 0.01$ & $(++)$ & - & Did not float & $1595.5 \pm 0.09$ \\
\hline F5 & $119.5 \pm 0.31$ & $8.25 \pm 0.02$ & $(+++)$ & 3 & $5 \mathrm{~min}$ & $>1595.5$ \\
\hline F6 & $120 \pm 0.43$ & $8.30 \pm 0.03$ & $(+++)$ & 10 & $>20 \mathrm{~h}$ & $>1595.5$ \\
\hline
\end{tabular}

Gelling Study: (+) Gels after few minutes dispersed rapidly, (++) Gelation immediate remains for $12 \mathrm{~h},(+++)$ Gelation immediate remains for more than $12 \mathrm{~h}$ 


\section{In vitro gelation study}

Gelling studies were carried out using $0.1 \mathrm{~N} \mathrm{HCl} / \mathrm{pH} 1.2$ and the obtained data were represented in table 2. Gelation occurs when the insoluble calcium carbonate solubilize when it comes in contact with acidic medium releasing carbon dioxide and calcium ions. The calcium ions interact with the anionic polymer (sodium alginate) in the formulation causing instantaneous gelation and provide a gel barrier that restricts drug release [18].

It was noted that formulation F5 and F6 containing $250 \mathrm{mg}$ and $300 \mathrm{mg}$ of sodium alginate resulted in the gelation which remained for more than $12 \mathrm{~h}$ providing the sustained release of the drug, which concludes that as the concentration of anionic polymer increases the gelling capacity also increases.

\section{Viscosity studies}

The formulation should have an optimum viscosity that will allow ease of administration and swallowing as a liquid and produce satisfactory gel strength for use as a delivery vehicle. Results of viscosity for formulations F1 to F6 are shown in table 2. The formulations showed an increase in viscosity with increasing the concentration of gel forming polymer sodium alginate as a consequence of the increase in chain interaction. The concentration of sodium alginate $(250 \mathrm{mg}$ and $300 \mathrm{mg}$ ) was found to produce a satisfactory viscosity increase which provides sustained release of the drug. Calcium carbonate also contributes to increasing the viscosity of the formulations.

\section{In vitro floating study}

The formulated floating in-site gelling system of diltiazem hydrochloride employed $\mathrm{NaHCO}_{3}$ or $\mathrm{CaCO}_{3}$ as a gas generating agent. The in vitro floating test revealed the ability of F6 formulation to maintain buoyant for more than $12 \mathrm{~h}$ (table 2). Regarding the floating lag time, it was observed that formulae F5 and F6 showed floating within 3 and $10 \mathrm{~min}$ respectively. The basic mechanism behind floating was because calcium carbonate solubilized and effervesced upon contact with acidic medium releasing calcium ion and carbon dioxide $\left(\mathrm{CO}_{2}\right)$. The evolved $\mathrm{CO}_{2}$ gas was entrapped in the gel causing floatation. The incorporation of sodium bicarbonate improves floating behavior by providing an additional source for $\mathrm{CO}_{2}$ gas generation $[19,20]$. The calcium ion reacted with polymers produced a cross-linked three-dimensional gel network and swelled structure of polymers might restrict the further diffusion of $\mathrm{CO}_{2}$ and drug molecule and has resulted in an extended period of floating lag time and drug release of the formulation (F5 and $\mathrm{F} 6$ ) respectively.

\section{Measurement of water uptake by the gel}

The formulation exhibited water uptake which is observed in the range of $10-107 \%$ as shown in table 3 . The release of the drug from the polymer matrix depends on the amount of water associated with the system. The release of the drug may involve the penetration of the water into the matrix and simultaneously release the drug via diffusion or dissolution. The water associated with the formulation at any point in the time can be determined by the simple test for all the formulation of sodium alginate based insitu gel of diltiazem hydrochloride. From the study, it was concluded that formulation F6 containing $300 \mathrm{mg}$ of the sodium alginate resulted in $100 \%$ water uptake, in turn, a good release of the drug from the polymer.

Table 3: Water uptake by gel $(n=3)$ (average \pm SEM)

\begin{tabular}{|c|c|c|c|c|c|c|}
\hline Formulation code & F1 & F2 & F3 & F4 & F5 & F6 \\
\hline Initial Wt (g) & $10.04 \pm 0.14$ & $10.26 \pm 0.03$ & $10.48 \pm 0.03$ & $11.3 \pm 0.04$ & $16.22 \pm 0.0 .04$ & $18.49 \pm 0.02$ \\
\hline Time $(\mathrm{H})$ & Water gain $(\mathrm{g})$ & & & & & \\
\hline 0 & $10.04 \pm 0.06$ & $10.26 \pm 0.26$ & $10.48 \pm 0.05$ & $11.3 \pm 0.03$ & $16.22 \pm 0.04$ & $18.49 \pm 0.03$ \\
\hline 1 & $11.6 \pm 0.09$ & $12.22 \pm 0.06$ & $12.08 \pm 0.02$ & $10.84 \pm 0.03$ & $17.11 \pm 0.04$ & $21.44 \pm 0.03$ \\
\hline 2 & Dissolved & Dissolved & $12.52 \pm 0.02$ & $10.89 \pm 0.02$ & $18.27 \pm 0.02$ & $28.99 \pm 0.02$ \\
\hline 3 & Dissolved & Dissolved & Dissolved & $11.32 \pm 0.04$ & $19.35 \pm 0.02$ & $38.12 \pm 0.03$ \\
\hline 4 & Dissolved & Dissolved & Dissolved & $13.06 \pm 0.03$ & $20.40 \pm 0.03$ & $38.40 \pm 0.02$ \\
\hline
\end{tabular}

\section{In vitro drug release study}

The in vitro release study of diltiazem hydrochloride from all six formulae in $0.1 \mathrm{NH}_{4} \mathrm{Cl}$ was conducted for a period of $7 \mathrm{~h}$ and the result was shown in fig. 1 . The effect of polymer concentration on in vitro drug release from the formulation is shown in fig. 1. A significant decrease in the rate and extent of the drug release was observed with the increase in polymer concentration in in-situ gelling preparation. These may be attributed to the increase in density of the polymer matrix and also an increase in diffusion path length which the drug molecules have to pass. The sodium alginate and HPMC with a primary role in the sol-gel phenomenon and buoyant also affected the release rate to some extent. Formulation F4, F5, F6 was shown to have extended drug release until the end of $7 \mathrm{~h}$.

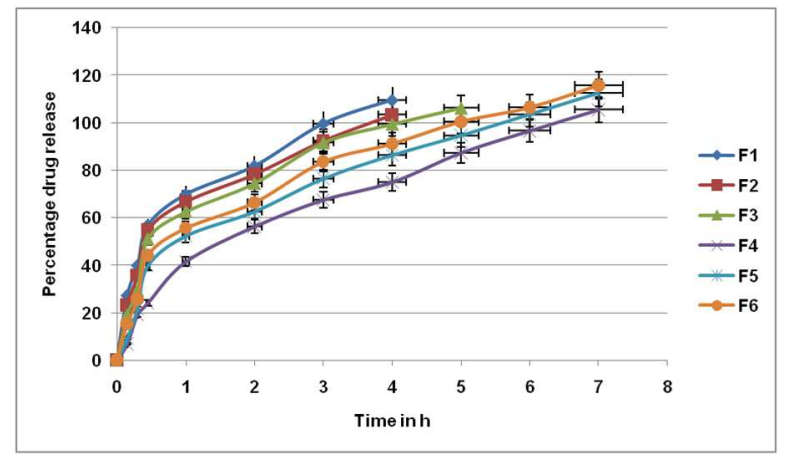

Fig. 1: In vitro drug release of diltiazem hydrochloride gel (F1, $\mathrm{F} 2, \mathrm{F3}, \mathrm{F4}, \mathrm{F5}, \mathrm{F6})$ in $0.1 \mathrm{NH}_{4} \mathrm{Cl}(\mathrm{n}=3)$ (average $\pm \mathrm{SEM}$ )

\section{CONCLUSION}

In the present study, various in-situ gelling liquid oral formulation of diltiazem hydrochloride was prepared. The study as shown that by modifying the concentration of viscosity enhancing polymer and the use of HPMC, calcium carbonate, the release can be modulated to the desired rate. The incorporation of the sodium bicarbonate inappropriate amount was able to shorten the floating lag time and thereby affecting even the drug release behaviour from the in-situ gel. The prepared floating in-situ gel of diltiazem hydrochloride has the feasibility of sustaining the drug release while remaining in the stomach. So this system is of promising use in the treatment of angina pectoris.

\section{ACKNOWLEDGEMENT}

Authors thank the management of Jaya College of Paramedical Sciences, College of Pharmacy, Thiruninravur, Chennai, Tamil Nadu for providing financial support and facilities to conduct this research work.

\section{CONFLICT OF INTERESTS}

Declared none

\section{REFERENCES}

1. Peppas N, Langer R. New challenges in biomaterials. Science 1994;263:1715-20.

2. Pande SD, Vaidya KP, Gulhane KP. Floating drug delivery system (fdds): a new way for oral drug delivery system. Int J Pharm Clin Sci 2013;3:1-13.

3. Nidhi D. In-situ gel: a novel approach of gastro retentive drug delivery. Asian J Pharm Sci Res 2013;3:1-14.

4. Plourde F, Motulsky A, Couffin-Hoarau AC, Hoarau D, Ong H, Lerour JC. The first report on the efficacy of l-alanine based In- 
situ-forming implants foe the long-term parenteral delivery of drugs. J Controlled Release 2005;108:433-41.

5. Khan AD, Meenakshi B. Floating drug delivery system: an overview. Int J PharmTech Res 2010;2:2497-505.

6. Miyazaki S, Endo K, Kawasaki N, Kubo W, Watanale H, Attwood D. Oral sustained delivery of paracetamol from in situ gelling xyloglucan formulations. Drug Dev Ind Pharm 2003;29:113-9.

7. Modi SA, Gaikwad PD, Bankar VH, Pawar SP. Sustained release drug delivery system: a review. Int J Pharm Res Dev 2011;2:147-60.

8. Moin Afrasim, Shiva kumar HG. Formulation of sustained release Diltiazem matrix tablet using hydrophilic gum blends. Top J Pharm Res 2010;9:283-91.

9. Nayak Amitkumar, Maji Ruma, Das Biswarup. Gastroretentive drug delivery system: a review. Asian J Pharm Clin Res 2010;3:1-10.

10. Madan M, Bajaj A, Lewis S, Udapa N, Baig JA. In-situ forming polymeric drug delivery. Indian J Pharm Sci 2009;71:242-51.

11. Moin A, Reddy MM, Reddy DJ, Shivakumar HG. Formulation of sustained release matrix tablet using chitosan/ghatti. gum. poly electrode complex Sch. Res Lib 2011;3:119-28.

12. Thomas LM. Formulation and evaluation of floating oral in-situ gel of metronidazole. Int J Pharm Pharm Sci 2014;6:265-9.

13. Hasan MJ, Kamal BA. Formulation and evaluation of ranitidine hydrochloride are floating In situ gel. Int J Pharm Pharm Sci 2014;6(Suppl 2):401-5.
14. Shivaraju, Parthiban S, Senthilkumar SK. Preparation and evaluation of ornidazole in situ gelling system for gastro retentive drug delivery. Int J Pharm 2013;3:62-9.

15. Al-Mamun MA, Rahman MR, Biswas S, Kundu SK, Rayhan J. Formulation and bioequivalence evaluation of an extended release solid drug delivery system for metronidazole using using eudragit $\mathrm{nm} 30 \mathrm{~d}$ and methocel premium $\mathrm{K} 4 \mathrm{~m}$ as retardant material. Am J Adv Drug Delivery 2014;2:39-51.

16. Patel DM, Patel CN. Formulation and evaluation of floating oral in-situ gelling system of amoxicillin. ISRN Pharm 2011;1:1-8.

17. Patel JK, Chavda JR, Modasiya Mk. Floating in-situ gel based on alginate as a carrier for stomach specific drug delivery of famotidine. Int J Pharm Sci Nanotech 2010;3:1092-104.

18. Choi BY, Park HJ, Hwang SJ, Park JB. Preparation of alginate boads for floating drug delivery system: effects of $\mathrm{CO}_{2}$ gasforming agents. Int J Pharm 2002;239:81-91.

19. Google J, Vandrbist F, Amighi K. Development and evaluation of new multiple-unit levodopa sustained-release floating dosage forms. Int J Pharm 2007;334:35-41.

20. Rajinikanth PS, Mishra B. Floating in-situ gelling system for stomach site-specific delivery of clarithromycin to eradicate Helicobacter pyroli. J Controlled Release 2008;125:33-41.

\section{How to cite this article}

- A Maheswaran, J Padmavathy, V Nandhini, D Saravanan, P Angel. Formulation and evaluation of floating oral In situ gel of diltiazem hydrochloride. Int J Appl Pharm 2017;9(1):50-53. 